\title{
Hyperinsulinism: molecular aetiology of focal disease
}

\author{
F Ryan, D Devaney, C Joyce, A Nestorowicz, M A Permutt, B Glaser, D E Barton, \\ P S Thornton
}

\begin{abstract}
Persistent hypoglycaemia in infancy is most commonly caused by hyperinsulinism. A case is reported of the somatic loss of the maternal 11p in an insulin secreting focal adenoma in association with a germline SUR-1 mutation on the paternal allele in a baby boy with hyperinsulinism diagnosed at 49 days old. A reduction to homozygosity of an SUR-1 mutation is proposed as a critical part of the cause of focal hyperinsulinism.

(Arch Dis Child 1998;79:445-447)
\end{abstract}

Keywords: hyperinsulinism; sulphonylurea receptor; mutational analysis

Persistent hypoglycaemia in infancy is most commonly caused by hyperinsulinism. It is characterised by profound hypoglycaemia caused by inappropriate secretion of insulin. Hyperinsulinism may be inherited in both autosomal recessive ${ }^{1}$ and dominant ${ }^{2}$ forms. At the molecular level, mutations in the sulphonylurea receptor (SUR-1) ${ }^{3}$ and the potassium channel subunit (KIR6.2) ${ }^{4}$ have been identified in autosomal recessive forms of the disease. Somatic loss of maternal chromosome $11 \mathrm{p}$ has been demonstrated in non-familial cases with areas of focal adenomatosis ${ }^{5}$ and in adenomas $^{6}$ of the pancreas. In these reports, the minimum region of chromosome $11 \mathrm{p}$ lost included the SUR-1 and KIR6.2 genes, as well as at least two maternally expressed imprinted tumour suppresser genes ( 19 and P57KIP2).

We report the somatic loss of the maternal $11 \mathrm{p}$ in an insulin secreting focal adenoma in association with a germline SUR-1 mutation on the paternal allele in a patient with hyperinsulinism. We propose a reduction to homozygosity of an SUR-1 mutation as a critical part of the cause of focal hyperinsulinism.

\section{Case report}

A baby boy, with no family history of hypoglycaemia, presented with hypoglycaemia on day 42 of life. Hyperinsulinism was diagnosed at 49 days based on the finding of increased glucose requirement $(15 \mathrm{mg} / \mathrm{kg} / \mathrm{min})$ to maintain euglycaemia. At a plasma glucose of $1.7 \mathrm{mmol} / \mathrm{l}$ the patient's insulin concentration was $297 \mathrm{pmol} / 1$ (normal < $14 \mathrm{pmol} / \mathrm{l}$ ); at a plasma glucose of $0.4 \mathrm{mmol} / 1$, insulin was $75 \mathrm{pmol} / 1$, 3-hydroxybutyrate was suppressed at $0.02 \mathrm{mmol} / 1$ (normal $>1.5 \mathrm{mmol} / \mathrm{l}$ ), and the patient had a glycaemic response to glucagon of $>1.7 \mathrm{mmol} / \mathrm{l}$. Diazoxide and octreotide treatment was unsuccessful and surgery was performed on day 84 .

At surgery an adenoma was palpated and partial pancreatectomy (approximately 40\%) performed. Histology confirmed an insulin staining adenoma with normal pancreatic tissue in the surrounding area. The patient recovered well, tolerated a 13 hour fasting interval at age 4 months, and has had no subsequent hypoglycaemia.

Genomic DNA was extracted from patient and parental peripheral blood leucocytes, and from patient paraffin embedded tissue using standard techniques. SUR-1 exon 10 sequences were amplified using standard polymerase chain reaction (PCR) conditions (GibcoBRL; Life Technologies, Paisley, UK) using exon 10 primers SUR-10F (5'-GTGGAGACGACCCGCA GGAAGGAG-3') and SUR-10R (5'-CCTT GCATGTACGCAGCAGCACCC-3'). Equal quantities of PCR product was digested for at least two hours with Bsr1 using conditions as described by the manufacturer. Bsr1 digestion of wild-type product yields two fragments of 66 and 50 base pairs. The mutated allele remains uncut. For GATA23FO6 and $\mathrm{TH}^{7}$ microsatellite analysis, PCR was performed as above and analysed on a $7 \%$ Long Ranger gel run on a Pharmacia ALF automatic sequencing system (Pharmacia BioFech, St Albans, UK).

\section{Results}

Patient leucocyte DNA was screened for 24 previously identified SUR-1 mutations ${ }^{8}$ and 2 KIR6.2 mutations; heterozygosity for an SUR 1 intron 10 splice site mutation $(1630+1$ $\mathrm{G} \rightarrow \mathrm{T}$ ) was discovered. This mutation had previously been identified in three other patients with hyperinsulinism. One was a compound heterozygote for this and another SUR-1 mutation, whereas in the other two the mutation was identified on the paternal allele with no mutation identified on the maternal allele. As this mutation destroys a Bsr 1 restriction site, enzyme digestion of exon 10 PCR product was used to identify the mutation in patient and parental samples (fig 1), demonstrating that the mutation was paternally derived. Analysis of DNA from the patient's normal pancreatic tissue demonstrated a heterozygous pattern of normal and mutant allele. In contrast, DNA extracted from adenoma tissue contained mostly mutant allele.

To investigate if this was the result of loss of the maternal allele we performed microsatellite analysis using $11 \mathrm{p}$ specific markers GATA23FO6 and TH. TH lies approximately 


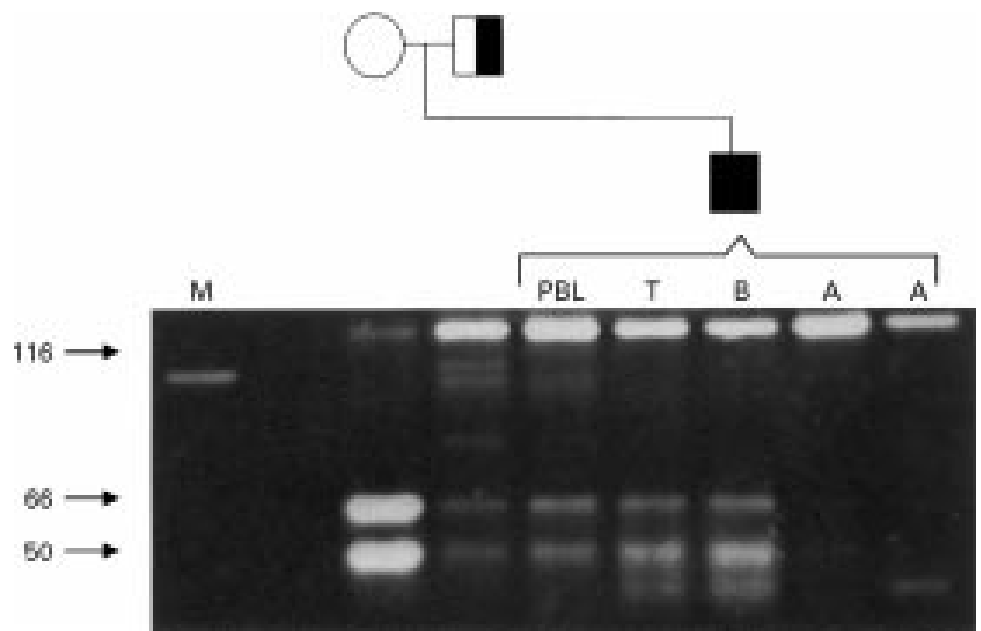

Figure 1 Mutation detection in patient and parental DNA samples. Agarose gel showing products of BsrI restriction of SUR exon 10 sequences. The figure shows homozygous wild-type pattern for the maternal DNA, heterozygous $(1630+1 G \rightarrow T)$ mutation in the paternal, patient leucocyte and normal pancreatic tissue, but reduction to almost complete homozygous $1603+1 G \rightarrow T$ mutation in patient adenoma. PBL, peripheral blood leucocytes; $T$, tail of pancreas (normal); $B$, body of pancreas (normal); $A$, adenoma; $M, 100$ base pair marker.

30 centimorgans telomeric to the SUR-1 gene with the GATA23FO6 between the $\mathrm{TH}$ and SUR-1. The results demonstrated a Mendelian inheritance pattern in the patient's leucocyte and normal pancreatic tissue, and a loss of the maternal $11 \mathrm{p}$ in the adenoma (fig 2). Our results indicate that the hyperinsulinism in this case is as a result of a reduction to homozygosity of the SUR-1 mutation in the adenoma tissue.

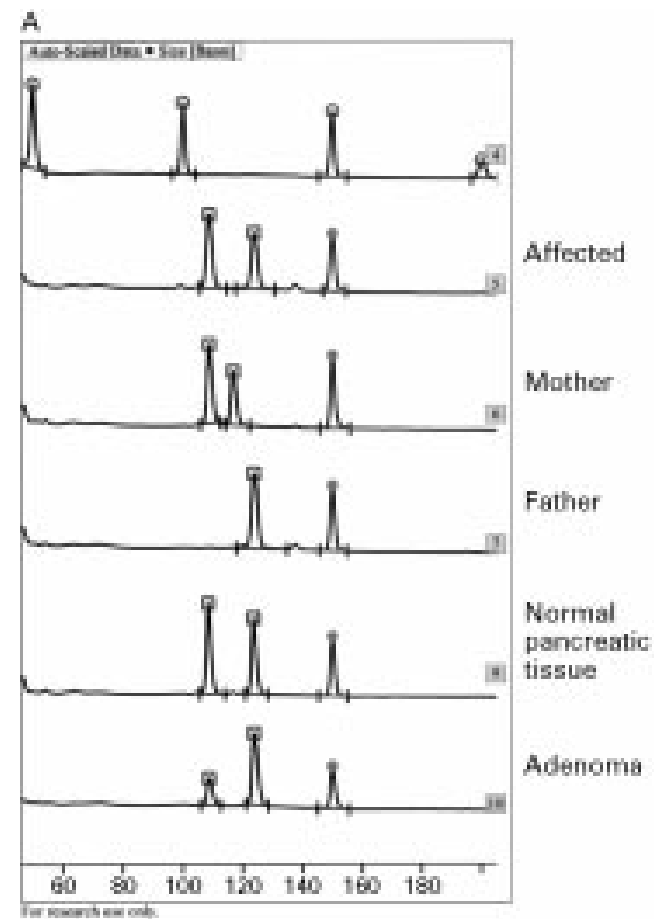

\section{Discussion}

de Lonlay and colleagues ${ }^{5}$ demonstrated loss of heterozygosity $(\mathrm{LOH})$ in focal hyperplasia of the pancreas. They proposed that the hyperplasia was either caused by a loss of the imprinted tumour suppresser genes H19 or P57KIP2, or an expression imbalance between $\mathrm{H} 19$ and IGF II. Their studies explain the hyperplasia in focal disease but do not adequately address the hypersecretion of insulin in the focal tissue. Beckwith-Wiedemann syndrome, a condition in which $20 \%$ have $\mathrm{LOH}$ of chromosome $11 \mathrm{p}$ (the region containing the SUR-1 locus) is associated with hyperinsulinism in $30 \%$ of cases, but the occurrence of hyperinsulinism in these patients does not correlate with the occurrence of the LOH. ${ }^{7}$ We propose a model where the somatic loss of the maternal $11 \mathrm{p}$ is the causative factor for focal hyperplasia but that the hyperplasia itself is not sufficient to cause insulin hypersecretion. With the additional presence of a paternally derived SUR-1 mutation, there is a reduction to homozygosity for SUR-1 in focal cells resulting in dysregulation of insulin secretion and ultimately to the hyperinsulinism phenotype. Resection of the affected tissue resulted in a cure in a similar fashion to the partial pancreatectomy performed by de Lonlay et al in focal hyperplasia, unlike autosomal recessive hyperinsulinism in which a $95 \%$ pancreatectomy is often insufficient. In conclusion, this case demonstrates a novel mechanism for the apparent sporadic inheritance of disease considered an autosomal recessive disorder.

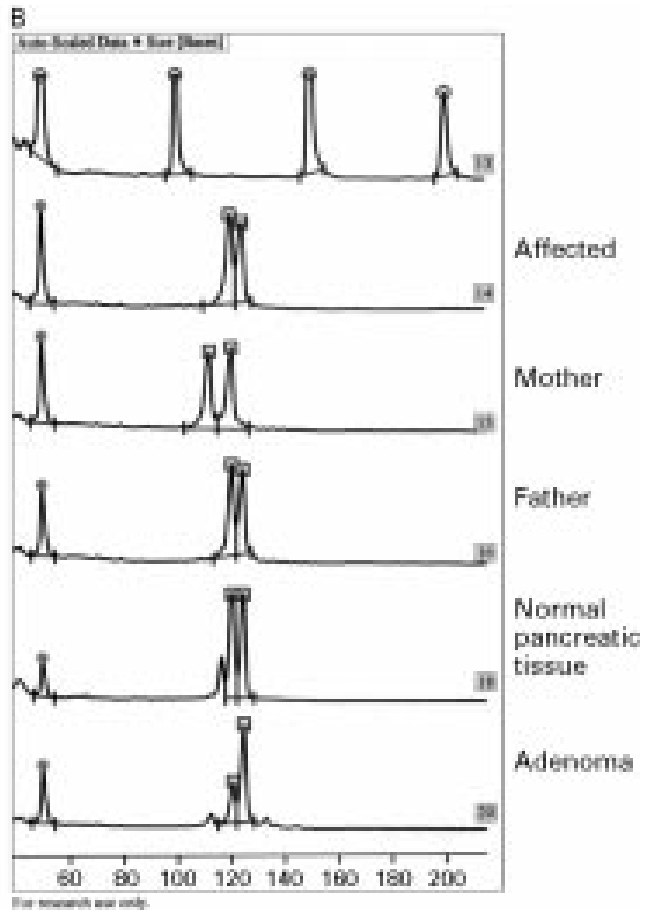

Figure 2 Microsatellite analysis of patient and parental DNA samples. ALF trace of (A) TH and (B) GATA23F06 microsatellite analysis. Lanes 4 and 13, size marker; lanes 5, 6, 7, and 13, 14, 15, peripheral blood leucocyte DNA from patient, mother, and father respectively; lanes 9, 10, and 18,20, DNA from normal and adenoma tissue respectively. $A$ Mendelian inheritance pattern is seen in normal tissue and almost complete loss of the maternal allele is seen in adenoma tissue. PCR products were identified by electrophoresis on a Pharmacia ALF. Open squares indicate PCR products, closed circles are internal size marker; open circles are external size marker. 
The authors thank Professor Andrew Green for helpful discussion. MAP is the recipient of an NIH grant.

1 Thornton PS, Sumner AE, Ruchelli ED, Spielman RS, Baker, L, Stanley CA. Familial and sporadic hyperinsulinism: histopathologic findings and segregation analysis support a single autosomal recessive disorder. $\mathcal{f}$ Pediat 1991;119:721-4.

2 Thornton PS, Satin-Smith MS, Herold K, et al. Familial hyperinsulinism with apparent autosomal dominant inheritance: clinical and genetic differences from the autosomal recessive variant. F Pediatr 1998;131:9-14.

3 Thomas PM, Cote CJ, Wohllk N, et al. Mutations in the sulphonylurea receptor gene in familial hyperinsulinaemic hypoglycaemia of infancy. Science 1995;268:426-9

4 Nestorowich A, Inagaki N, Gonoi T, et al. A nonsense mutation in the inward rectifier potassium channel gene, Kir6.2, is associated with familial hyperinsulinism. Diabetes 1997; 46:1743-8.

5 de Lonlay P, Fournet JC, Rahier J, et al. Somatic deletion of the imprinted $11 \mathrm{p} 15$ region in sporadic persistent hyperinsulinaemic hypoglycaemia of infancy is specific of focal adenomatous hyperplasia and endorses partial pancreatectomy. F Clin Invest 1997;100:802-7.

6 Patel P, O'Rahilly S, Buckle V, Nakamure Y, Turner RC, Wainscoat JS. Chromosome 11 allele loss in sporadic insulinoma. F Clin Pathol 1990;43:377-8.

7 Slatter R, Elliott M, Carrera M, Schofield FM, Barton DE, Maher ER. Mosiac uniparental disomy in BeckwithWiedemann syndrome. F Med Genet 1994;31:749-53.

8 Nestorowicz A, Glaser B, Wilson B, et al. Genetic heterogeneity in familial hyperinsulinism. Human Molecular Genetics 1998;7:1119-28.

\section{Acute scrotal swelling}

Beware the facts that everybody knows. Everybody knows, for instance, and paediatric textbooks confirm, that epididymitis is rare in children. Several case series, however, have suggested that this may not be true.

In Salt Lake City, USA 64 of 90 boys with acute scrotal pain or swelling had epididymitis and 50 of the 64 were under 12 years old (Howard A Kadish and Robert G Bolte. Pediatrics 1998;102:73-6). Of the remaining 26, 13 had testicular torsion (TT) and 13 torsion of the appendix testis (TAT). Fewer of those with epididymitis presented within 12 hours of symptom onset and they were more likely than those with torsion to have fever, a history of previous similar pain, or dysuria, although each of these features was present in fewer than $20 \%$ of boys with epididymitis. The testicular lie was normal in all boys with epididymitis or TAT but abnormal in almost half of those with TT. The testis as a whole was tender in all those with TT, $69 \%$ of those with epididymitis, and $31 \%$ of those with TAT, but all boys with TAT had localised tenderness at the superior pole of the testis. The cremasteric reflex was absent in all patients with $\mathrm{TT}, 14 \%$ with epididymitis, and none with TAT. Scrotal erythema or oedema was more common in epididymitis $(67 \%)$ than in TT $(38 \%)$ or TAT ( $8 \%$, one patient). Coloured Doppler ultrasound showed decreased blood flow in all seven patients with TT in whom it was performed, one of 29 with epididymitis, and neither of two with TAT. Ten of the 13 boys with TT had salvageable testes.

None of this should lead clinicians into delaying surgery for boys who might have testicular torsion. In Salt Lake City they operate right away if the diagnosis is at all likely and do Doppler studies only when there is serious doubt.

ARCHIVIST 